\title{
Cutaneous melanoma: From pathogenesis to therapy (Review)
}

\author{
GIULIA C. LEONARDI ${ }^{1}$, LUCA FALZONE $^{1}$, ROSSELLA SALEMI $^{1}$, ANTONINO ZANGHİ $^{2}$, \\ DEMETRIOS A. SPANDIDOS ${ }^{3}$, JAMES A. McCUBREY $^{4}$, SAVERIO CANDIDO $^{1 *}$ and MASSIMO LIBRA ${ }^{1,5^{*}}$ \\ ${ }^{1}$ Department of Biomedical and Biotechnological Sciences, University of Catania, 95123 Catania; \\ ${ }^{2}$ Department of Medical and Surgical Sciences and Advanced Technology 'G.F. Ingrassia', \\ University of Catania, 95125 Catania, Italy; ${ }^{3}$ Laboratory of Clinical Virology, Medical School, \\ University of Crete, 71003 Heraklion, Crete, Greece; ${ }^{4}$ Department of Microbiology and Immunology, \\ Brody School of Medicine at East Carolina University, Greenville, NC 27858, USA; ${ }^{5}$ Research Center of \\ Tumor Prevention, Diagnosis and Cure (CRS PreDiCT), University of Catania, 95123 Catania, Italy
}

Received December 13, 2017; Accepted February 8, 2018

DOI: $10.3892 / \mathrm{ijo} .2018 .4287$

\begin{abstract}
In less than 10 years, melanoma treatment has been revolutionized with the approval of tyrosine kinase inhibitors and immune checkpoint inhibitors, which have been shown to have a significant impact on the prognosis of patients with melanoma. The early steps of this transformation have taken place in research laboratories. The mitogen-activated protein kinase (MAPK) pathway, phosphoinositol-3-kinase (PI3K) pathway promote the development of melanoma through numerous genomic alterations on different components of these pathways. Moreover, melanoma cells deeply interact with the tumor microenvironment and the immune system. This knowledge has led to the identification of novel therapeutic targets and treatment strategies. In this review, the epidemiological features of cutaneous melanoma along with the biological mechanisms involved in its development and progression are summarized. The current state-of-the-art of advanced stage melanoma treatment strategies and the currently available evidence of the use of predictive and prognostic biomarkers are also discussed.
\end{abstract}

\section{Contents}

1. Epidemiology and risk factors

2. The genesis of malignant melanoma

3. Melanoma biology

Correspondence to: Professor Massimo Libra, Department of Biomedical and Biotechnological Sciences, Pathology and Oncology Section, University of Catania, Via Santa Sofia 97, 95123 Catania, Italy

E-mail:m.libra@unict.it

*Joint senior authorship

Key words: melanoma, mitogen-activated protein kinase pathway, phosphoinositol-3-kinase pathway, biomarkers, targeted therapy, immunotherapy
4. Principles of medical treatment

5. Predictive biomarkers in melanoma

6. Conclusions

\section{Epidemiology and risk factors}

The worldwide incidence of cutaneous melanoma has been increasing annually at a more rapid rate compared to any other type of cancer (1). In 2012, 232,000 new cases of melanoma and 55,000 deaths were registered worldwide, ranking 15 th among most common cancers worldwide (2). The incidence of cutaneous melanoma varies greatly between countries and these different incidence patterns are ascribed to variations in racial skin phenotype, as well as differences in sun exposure. Moreover, unlike other solid tumors, melanoma mostly affects young and middle-aged individuals (median age at diagnosis, 57 years). The incidence increases linearly after the age of 25 years until the age of 50 years, and then decreases, particularly in the female sex. When analyzing incidence data in relation to sex, women are more frequent in younger aged groups, while the male sex prevails from the age of 55 onwards (3).

Ultraviolet (UV) light radiation from sunlight is the main environmental risk factor for melanoma skin cancer development (4-6). The increased risk of melanoma due to sun exposure is directly associated with the UV level and in particular to the UV-B spectrum (5). In addition, sun exposure patterns and timing have been associated in a number of studies with an increased risk of melanoma. In particular, intense and intermittent sun exposure (typical of sunburn history) is associated with a higher risk compared to a chronic continuous pattern of sun exposure that is more frequently associated with actinic keratosis and non-melanoma skin cancers (7-10). Furthermore, a history of sunburn in childhood or adolescence is associated with the highest risk of developing melanoma and individuals experiencing $>5$ episodes of severe sunburn have a 2 -fold increased risk $(8,11)$. UV-A exposure from artificial sources has been also linked to an increased risk of developing melanoma. The follow-up of patients with psoriasis receiving UV-A radiation phototherapy, as well as in individuals using sunbeds 
has revealed an increased risk of melanoma in this population $(12,13)$. Specifically, several studies and a meta-analysis have demonstrated a positive association between the risk of developing melanoma and the amount of sunbed usage, particularly from a young age, thus raising a major public health issue $(12,14,15)$. UV light from sunbeds has been formally classified as a human carcinogen (14). No other environmental factors, including tobacco/smoke addiction, have been associated with melanoma (1).

In addition, host risks factors, such as the number of congenital and acquired melanocytic nevi, genetic susceptibility and a family history play a central role in the development of melanoma (16-18). Approximately $25 \%$ of melanoma cases arise on a pre-existing nevus (19). In this context, not only the total number of nevi, but also the size and type of nevi, are individually associated with an increased risk of melanoma (20-23).

As regards genetic susceptibility, the polymorphisms of the melanocortin 1 receptor $(M C 1 R)$ gene, are responsible for the different human skin-color phenotypes. Individuals with characteristics, such as red hair, a light complexion and light eyes exhibit a low pigmentation, with a consequent heightened sensitivity to UV exposure (24). Approximately 7-15\% of melanoma cases occur in patients with a family history of melanoma (25). However, true hereditary melanoma (i.e., multi-generational, unilateral lineage, multiple primary lesions and early onset of the disease) are infrequent; the familial clustering of the disease is considered to be responsible for the presence of a transmitted genetic mutation $(25,26)$. Over the past years, melanomas have also been found to arise in families that are generally prone to specific patterns of malignancies, such as the familial atypical multiple mole-melanoma syndrome (FAMMM syndrome) and its variant, the melanoma-astrocytoma syndrome (MAS) (26). Germline mutations in cyclin-dependent kinase inhibitor $2 \mathrm{~A}(C D K N 2 A$ or p16) and, less common, mutations in cyclin-dependent kinase $4(C D K 4)$ are the most frequent genetic abnormalities identified in these families (26-28). Other inherited conditions associated with an increased risk of developing melanoma are xeroderma pigmentosum, familial retinoblastoma, Lynch syndrome type II and Li-Fraumeni cancer syndrome (25).

\section{The genesis of malignant melanoma}

Melanocytes are neural crest-derived cells that can be found principally in the basal epidermis and in hair follicles, along mucosal surfaces, meninges and in the choroidal layer of the eye (29). In response to UV-induced DNA damage, skin keratinocytes produce the melanocyte stimulating hormone (MSH) that binds the melanocortin receptor 1 (MC1R) on the melanocytes that than produce and release melanin. The melanin pigment ultimately operates as a shield for UV radiation, thus preventing further DNA alteration (30).

Cutaneous melanoma can be generally classified in the Caucasian population by its origin from chronically or intermittent sun-exposed skin that translate into different sites of origin, a degree of cumulative UV exposure, age at diagnosis, types of oncogenic drivers and mutational load (9). Indeed, melanomas in chronically sun-exposed skin usually appear in older-aged individuals ( $>55$ years), on chronically sun-exposed areas, such as the head and neck, as well as the dorsal region of the upper extremities. The main genetic drivers are B-Raf proto-oncogene $(B R A F)$, neurofibromin $1(N F 1)$ and $N R A S$ mutations, and usually melanomas associated with chronically sun-exposed skin have a high mutational load related to UV exposure $(9,31,32)$. On the other hand, melanoma associated with intermittent sun-exposed skin cases arise in younger-aged individuals ( $<55$ years), on less sun-exposed areas, such as the trunk and proximal extremities, and are usually associated with $\mathrm{BRAF}^{\mathrm{V} 600 \mathrm{E}}$ and a lower mutational load $(31,32)$.

Over the past years, a deeper understanding of melanoma development and biology has been reached. It has become clear that the development of fully-evolved melanoma from pre-neoplastic lesions is not represented by a single evolutionary pattern. Each melanoma subtype can evolve from different precursor lesions, and can involve different gene mutations and stage of transformation (33). An interesting finding is that BRAF is mutated in up to $80 \%$ of benign nevi, resulting in limited melanocyte proliferation through the oncogene-mediated activation of cell senescence $(34,35)$. These nevi remain indolent for decades also due to immune surveillance (36). Therefore, oncogenic BRAF alone is not sufficient for melanoma development and rarely benign nevi further progress to melanoma $(33,37)$. When this usually occurs, it is associated with the acquisition of subsequent mutations in key genes, such as TERT or CDKN2A. On the other hand, melanomas associated with chronic sun-exposed skin usually do not arise form pre-existing nevi, but from melanomas in situ or dysplastic lesions and carry a different set of mutations (33). Histological characterization is the current mainstay of melanocytic neoplasia diagnosis and the definition of their malignant potential. However, histopathology is sometimes associated with the equivocal characterization of these lesions, leading to their improper risk stratification (38). The increasing understanding of the biological determinants of melanoma evolution and their potential integration in the management of melanoma patients may lead to an improve diagnosis and the earlier recognition of lesions at an increased risk of progression, thus improving patient risk stratification (Fig. 1).

\section{Melanoma biology}

Cutaneous melanoma is one of the most aggressive forms of skin cancer and one of the leading causes of cancer-related mortality due its metastatic power. Several studies have demonstrated that melanoma spreading is the result of genetic mutations and tumor microenvironmental alterations, characterized by the overexpression of proteins able to favor tumor invasion and surrounding infiltration (39-44). In particular, a key role is played by the overexpression of matrix metalloproteinases (MMPs), particularly MMP-9 and MMP-2, that induces the degradation of the components of the extracellular matrix, thus favoring tumor cell infiltration and spreading through the bloodstream (40-42). The overexpression of these proteins and tumor microenvironmental alterations are mediated by genetic alterations and the dysregulation of the nuclear factor $(\mathrm{NF})-\kappa \mathrm{B}$ pathways. It has been demonstrated that MMP-9 overexpression observed in melanoma is caused by intragenic methylation phenomena that lead to protein overexpression (42). Furthermore, it has also been demonstrated that 


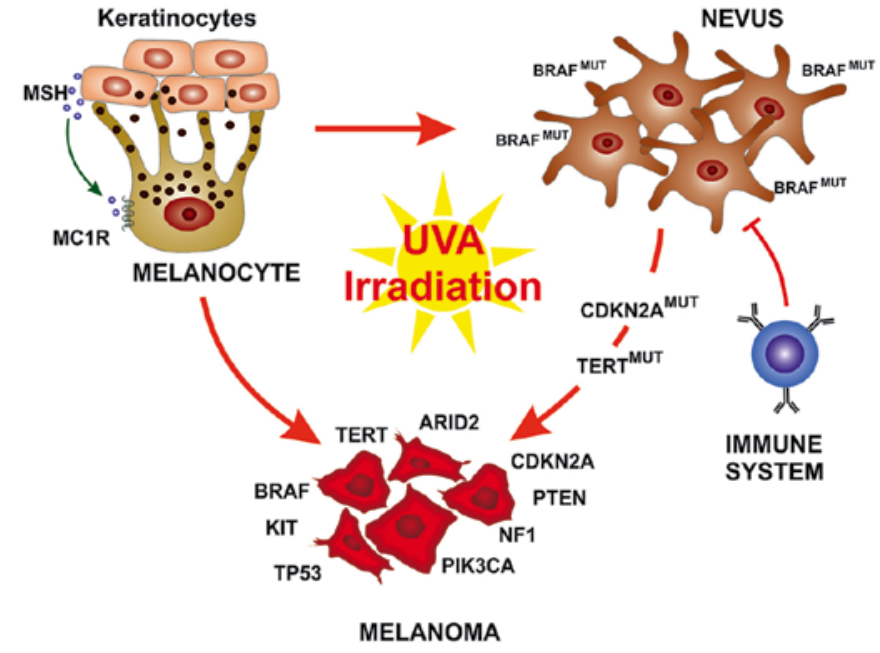

Figure 1. Melanocyte malignant transformation. Physiologically, keratinocytes induces melanocyte proliferation through the production of MSH hormone and its binding with the MC1R. UV-A irradiation induces melanocytes malignant transformation through two different mechanisms: The direct transformation of normal melanocytes in neoplastic cells through the occurrence of severa mutations affecting both proto-oncogene and tumor suppressor genes (TP53, $N F 1, P T E N$, etc.). The transformation of melanocytes into benign nevi that in $80 \%$ of cases harbor the mutation $\mathrm{BRAF}^{\mathrm{V} 600 \mathrm{E}}$. These nevi remain indolent for decades also due to immune surveillance; however, UV rays can determine the onset of additional genetic mutations, such as TERT and CDKN2A, that lead to the malignant transformation of the nevi. MSH, melanocyte-stimulating hormone; MC1R, melanocortin 1 receptor; BRAF, B-Raf proto-oncogene; CDKN2A, cyclin-dependent kinase inhibitor 2A; TERT, telomerase reverse transcriptase; ARID2, AT-rich interaction domain 2; PTEN, phosphatase and tensin homolog; NF1, neurofibromin 1; TP53, tumor protein p53; KIT, KIT proto-oncogene receptor tyrosine kinase.

$\mathrm{NF}-\kappa \mathrm{B}$ induces the overexpression of MMP-9 by the activation of osteopontin (OPN), another protein of the tumor microenvironment, thus playing a fundamental role in the development and progression of melanoma $(43,44)$.

Apart from tumor microenvironmental alterations, melanomas are associated with one of the greatest burdens of somatic genetic alterations of all human tumors $(45,46)$. The most frequent somatic mutations in chronically or intermittent sun-exposed skin melanomas affect genes that control central cellular process, such us proliferation (BRAF, NRAS and NF1), growth and metabolism [phosphatase and tensin homolog (PTEN) and KIT proto-oncogene receptor tyrosine kinase $(K I T)$ ], resistance to apoptosis [tumor protein p53 (TP53)], cell cycle control [cyclin-dependent kinase inhibitor $2 \mathrm{~A}$ $(C D K N 2 A)]$ and replicative lifespan [telomerase reverse transcriptase $(T E R T)](47,48)$. These genomic alterations typically lead to the aberrant activation of two main signaling pathways in melanoma: The RAS/RAF/MEK/ERK signaling cascade [also known as the mitogen-activated protein kinase (MAPK) pathway] and the phosphoinositol-3-kinase (PI3K)/AKT pathway (49).

The MAPK pathway is physiologically involved in the transduction of extracellular signals, such as growth factors and hormones, to the nucleus, leading to the expression of genes that are central drivers of cell proliferation, differentiation and survival $(50,51)$. In addition, it has been shown that MAPK activation is a critical player in the biology of different types of cancer and is the most frequent pathway aberrantly activated in melanoma (52). The PI3K pathway is normally involved in cellular homeostasis and its activation has been demonstrated to be central in different cancer types, including melanoma where it is the second most frequently activated pathway $(53,54)$.

Up to $90 \%$ of melanomas exhibit an aberrant MAPK pathway activation and this is a central step in melanoma development, being responsible for cell cycle deregulation and apoptosis inhibition $(50,55,56)$. Among the different mechanisms responsible for abnormal MAPK pathway signaling in melanoma, the most frequent genetic abnormalities are, by far, BRAF mutations $(37,47)$. Indeed, 37 to $50 \%$ of melanomas carry a somatic mutation in the $B R A F$ gene with the highest frequency in cutaneous melanomas derived from intermittent sun exposure damage (approximately 60\% carry a BRAF mutation) (31). Usually, BRAF mutations detected in cutaneous melanoma are missense mutations that determine amino acid substitution at valine 600. Approximately 80-90\% of BRAF mutations are V600E (valine to glutamic acid), while $5-12 \%$ are valine to lysine substitution $(\mathrm{V} 600 \mathrm{~K})$ and $\leq 5 \%$ are V600D (valine to aspartic acid) or V600R (valine to arginine) (57,58).

BRAF protein is a serine/threonine protein kinase of 766 amino acids organized in three domains: Two with regulatory function and one catalytic domain responsible for MEK phosphorylation (59). The catalytic domain is also responsible for maintaining the protein in its inactive conformation, through a hydrophobic interaction between the 'so-called' glycine-rich loop and the activation segment, making it inaccessible for ATP binding (59). In the BRAF ${ }^{\mathrm{V} 600 \mathrm{E}}$ mutation, hydrophobic valine is replaced by polar, hydrophilic glutamic acid, resulting in an abnormal flip of the catalytic domain that generates a constitutive active conformation with a kinase activity 500-fold higher than wild-type BRAF kinase $(60,61)$. Most of the non-V600E BRAF mutations act similarly through the alteration of glycine-rich loop and activation segment interaction, thus increasing BRAF kinase activity (61).

The second most common cause of aberrant signaling through the MAPK pathway in cutaneous melanoma is represented by NRAS activating mutations. NRAS is mutated in $15-30 \%$ of melanomas and in the majority of cases, these mutations are missense mutations of codon 12,13 or 61 (the latter account for $80 \%$ of all NRAS mutations in melanoma) $(31,62)$. Mutations of these codons lead to the prolongation of the NRAS-active GTP-bound state, thus abnormally maintaining NRAS signaling through both the MAPK and the PI3K pathways $(47,63,64)$. Importantly, $N R A S$ and $B R A F$ mutations are considered mutually exclusive; however, co-mutations can rarely occur (approximately $0.5 \%$ in treatment-naïve patients) (64).

NF1 is a tumor suppressor gene mutated in $10-15 \%$ of melanoma cases and is the third most frequently mutated gene in melanoma $(65,66)$. The NF1 protein regulates the RAS family by converting the active RAS-guanosine triphosphate (RAS-GTP) to the inactive RAS-guanosine diphosphate (RAS-GDP), thereby inhibiting downstream RAS signaling (67). Therefore, NF1 loss-of-function determines the hyperactivation of NRAS protein and thus, increased MAPK and PI3K pathways signaling $(65,67,68)$. NF1 genomic alterations are more frequent in melanomas associated with 
Table I. Milestone trials for the systemic treatment of advanced, unresectable melanoma.

\begin{tabular}{|c|c|c|c|c|}
\hline Trial name & Treatment & $\begin{array}{c}\text { Overall response } \\
\text { rate }(\%)\end{array}$ & $\begin{array}{l}\text { Median progression-free } \\
\text { survival (months) }\end{array}$ & $\begin{array}{c}\text { Median overall } \\
\text { survival (months) }\end{array}$ \\
\hline \multirow[t]{2}{*}{ BRIM3 $(87,121)$} & $\begin{array}{l}\text { Dacarbazine } \\
\text { versus }\end{array}$ & 5 & 1.6 & 9.7 \\
\hline & vemurafenib & 48 & 5.3 & 13.6 \\
\hline \multirow[t]{2}{*}{ coBRIM (93) } & $\begin{array}{l}\text { Vemurafenib } \\
\text { versus }\end{array}$ & 50 & 7.2 & 17.4 \\
\hline & vemurafenib + cobimetinib & 69.6 & 12.3 & 22.3 \\
\hline \multirow[t]{2}{*}{ BREAK-3 (86) } & $\begin{array}{l}\text { Dacarbazine } \\
\text { versus }\end{array}$ & 7 & 2.7 & Not reported \\
\hline & dabrafenib & 50 & 5.1 & 20 \\
\hline \multirow[t]{2}{*}{ COMBI-d (90) } & $\begin{array}{l}\text { Dabrafenib } \\
\text { versus }\end{array}$ & 51 & 8.8 & 18.7 \\
\hline & dabrafenib + trametinib & 67 & 11 & 25.1 \\
\hline \multirow[t]{2}{*}{ COMBI-v (89) } & $\begin{array}{l}\text { Vemurafenib } \\
\text { versus }\end{array}$ & 51 & 7.3 & 18 \\
\hline & dabrafenib + trametinib & 64 & 11.4 & 25.6 \\
\hline \multirow[t]{2}{*}{ CA184-024 (122) } & $\begin{array}{l}\text { Dacarbazine } \\
\text { versus }\end{array}$ & 10.3 & 3 & 9.1 \\
\hline & dacarbazine + ipilimumab & 15.2 & 3 & 11.2 \\
\hline \multirow[t]{2}{*}{ CheckMate 066 (88) } & $\begin{array}{l}\text { Dacarbazine } \\
\text { versus }\end{array}$ & 13.9 & 2.2 & 10.8 \\
\hline & nivolumab & 40 & 5.1 & Not reached \\
\hline \multirow[t]{3}{*}{ CheckMate 067 (123) } & $\begin{array}{l}\text { Ipilimumab } \\
\text { versus }\end{array}$ & 19 & 2.9 & 19.9 \\
\hline & $\begin{array}{l}\text { nivolumab } \\
\text { versus }\end{array}$ & 43.7 & 6.9 & 37.6 \\
\hline & ipilimumab + nivolumab & 57.6 & 11.5 & Not reached \\
\hline \multirow[t]{3}{*}{ KEYNOTE-006 (124) } & $\begin{array}{l}\text { Ipilimumab } \\
\text { versus }\end{array}$ & 11.9 & 2.8 & 16 \\
\hline & $\begin{array}{l}\text { pembrolizumab q2w } \\
\text { versus }\end{array}$ & 33.7 & 5.5 & Not reached \\
\hline & pembrolizumab q3w & 32.9 & 4.1 & Not reached \\
\hline
\end{tabular}

q2w, every 2 weeks; q3w, every 3 weeks.

chronically sun-exposed skin and are usually associated with a high number of various genomic mutations, including co-occurence with BRAF or NRAS mutations $(68,69)$.

The receptor tyrosine kinase KIT is physiologically involved in melanoma proliferation and survival through the PI3K/AKT and the RAS/RAF/MEK/ERK pathways. Somatic activating mutations in this gene have been found in $2-8 \%$ of all malignant melanomas and are more frequent in acral melanomas and with melanoma arising on intermitted sun-exposed skin $(70,71)$.

$B R A F, N R A S, N F 1$ and KIT genomic deregulations are considered driver alterations in melanoma development; however, a number of other genes are involved in the characterization of invasive and metastatic melanoma genotype. $T E R T$ promoter mutations confer proliferative advantage to melanoma cells and along with heterozygous $C D K N 2 A$ alterations, have been frequently detected in in situ melanoma (72). The $C D K N 2 A$ gene encodes for p16INK4A, a cyclin-dependent kinase inhibitor. The further bi-allelic inactivation of $C D K N 2 A$ is a subsequent step to the melanoma invasive phenotype, rarely observed in precursor lesions (72-74). PTEN is a tumor suppressor gene involved in cell cycle progression control. PTEN dysregulation is usually detected in vertical growth phase melanoma and metastases with a frequency of $10-30 \%$ of cutaneous melanoma $(47,75)$. Missense and frameshift mutations or chromosomal deletions are the most frequent alteration detected in PTEN but also epigenetic mechanisms and microRNAs post transcriptional regulation of PTEN expression have been found (76). The genomic alteration involving PTEN are usually mutually exclusive with NRAS mutations, but frequently co-occur with BRAF gain-of-function. This finds its biological rational in the loss of PTEN being associated with increased PI3K/AKT pathway activation $(77,78)$. Indeed, $B R A F$ mutations and PTEN loss-of-function together activate both the MAPK pathway and the PI3K pathway, thus being potentially equivalent to NRAS-only activation $(78,79)$. In the clinical setting, PTEN 
loss-of-function represents one of the mechanism responsible for the acquired resistance of BRAF mutant melanoma treated with BRAF inhibitors (80).

Even though a conclusive model of recurrent alterations leading to metastatic progression has yet to be elucidated, $\beta$-catenin-mediated WNT signaling activation has been shown to be associated with metastatic dissemination, as well as melanoma formation $(37,81)$. CTNNB1 ( $\beta$-catenin) gene mutations are detected in $2-4 \%$ of malignant melanomas and act through the stabilization of $\beta$-catenin and increased transcription of TCF/LEF-responsive target genes (82).

\section{Principles of medical treatment}

The majority of patients with newly-diagnosed melanoma have early-stage disease. For these patients, surgical excision represents the treatment of choice and is curative in the majority of cases (83). However, some patients will later relapse with disseminated disease, while approximately $10 \%$ of melanoma cases are diagnosed at an advanced stage, and are unresectable or already metastatic. Among stage IV tumors, approximately one-third have visceral and brain involvement at diagnosis, with a severe prognosis and lower probability to have a sustained response to treatment (84). For patients facing advanced-stage disease, melanoma treatment has been revolutionized since 2011, with the approval of several therapeutic agents. These agents include RAF and MEK kinase inhibitors, as well as immune checkpoint inhibitors [anti-cytotoxic T-lymphocyte-associated antigen 4 antibodies (anti-CTLA4) and anti-programmed cell death protein 1 antibody (anti-PD1)]. Indeed, in the advanced-stage setting, anti-PD1 and anti-CTLA4 antibodies (such as nivolumab, pembrolizumab and ipilimumab), as well as selective BRAF inhibitors (vemurafenib and dabrafenib) alone and/or in combination with MEK inhibitors (cobimetinib and trametinib) have shown promising results in clinical trials (Table I) (85-93). Currently, only the presence of BRAF ${ }^{\mathrm{V} 600 \mathrm{E}}$ mutation is evaluated in the clinical setting, as it is essential to drive the appropriate treatment strategy. Other driver mutations, such as NRAS, NF1, CKIT, CDKN2A and PTEN, have not yet been included in standard clinical practice. However, the identification of these genomic alterations can identify patients who may benefit of experimental approach in clinical trials.

Immunotherapy and kinase inhibitors are nowadays the backbone of systemic therapy, while chemotherapy is considered a second-line, or even further, treatment option (94-96) (Fig. 2). Anti-PD1 antibodies and, with lower magnitude anti-CTLA4 therapeutic agents, offer lower response rates, but potentially long durable responses $(85,91,92)$. In $\mathrm{BRAF}^{\mathrm{V} 600 \mathrm{E}}$ melanoma, there has been a reasonable approach to the use of BRAF inhibitors with MEK inhibitors. The combination has led to high response rates $(70 \%)$ and a rapid response induction and symptom control, with a progression-free survival of approximately 12 months $(89,90,93)$. To date, however, there are no available data from prospective trials on the optimal choice for frontline treatment and treatment sequence, at least to the best of our knowledge. Nivolumab and pembrolizumab have shown to be effective on BRAF mutant melanoma after BRAF inhibitor resistance has risen, but there are no similar data

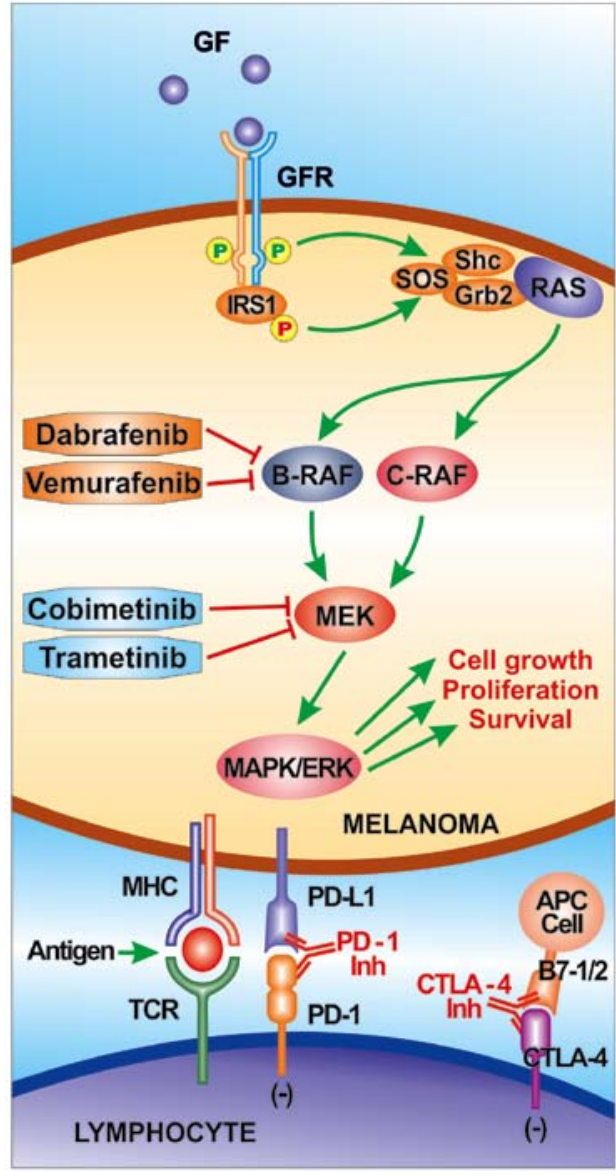

Figure 2. Medical treatment of melanoma. The therapeutic approaches for the melanoma treatment are based on serine/threonine protein kinase inhibitors and the news immune checkpoint inhibitors. Dabrafenib and vemurafenib are selective RAF inhibitors; cobimetinib and trametinib are selective MEK inhibitors; ipilimumab is a monoclonal antibody IgG1k anti-CTLA-4, while nivolumab and pembrolizumab are PD-1 monoclonal antibodies IgG4 and IgG4k anti-PD-1, respectively. All these monoclonal antibodies enhance the efficacy of the immune system that is able to recognize and eradicate tumor cells. GF, growth factor; GFR, growth factor receptor; IRS1, insulin receptor substrate 1; SOS, son of sevenless; Shc, SHC adaptor protein; Grb2, growth factor receptor bound protein 2; RAS: RAS proto-oncogene GTPase; BRAF, B-Raf proto-oncogene; C-RAF: RAF-1 proto-oncogene; MAPK, mitogen-activated protein kinase; ERK, mitogen-activated protein kinase 1; MHC, major histocompatibility complex; TCR, T-cell receptor; PD-1, programmed cell death protein 1; PD-L1, programmed death-ligand 1; APC, antigen-presenting cell; B7-1/2, CD80/CD86; CTLA-4, cytotoxic T-lymphocyte antigen 4.

for ipilimumab or for BRAF-inhibitor therapy in those with primary or secondary resistance to anti-PD-1 therapy (97-99). Currently, the combination of two different immune checkpoint inhibitors or the combination anti-PD1/anti-CTLA4 with targeted therapy must be considered an experimental approach in clinical trials. Each strategy has a clear benefit and basic research has demonstrated significant synergistic effects that need to be weighted with the potential increase in toxicity $(100,101)$.

The inclusion of patient characteristics [biochemical parameters of melanoma kinetics, such us lactate dehydrogenase (LDH)] and expected toxicity profile, as well as comorbidities and patient personal preferences are central elements to be taken into account for frontline treatment strategy definition. In this rapidly evolving landscape, it is of great importance the participation of patients in randomized clinical trials. 


\section{Predictive biomarkers in melanoma}

The identification of biomarkers that can predict patient benefits towards specific treatment strategies is a central goal of cancer research. BRAF mutations, particular BRAF ${ }^{\mathrm{V} 600 \mathrm{E}}$, is a typical predictive marker of response to RAF inhibitors. However, these patients almost invariably develop disease progression after a variable period of time and some patients can display primary resistance to BRAF (+/- MEK) inhibitors. Several studies have described the central role of acquired genetic mutations affecting the Ras/Raf/MEK/ERK and PI3K/PTEN/Akt/mTOR signaling pathways in inducing resistance to both chemotherapy and targeted therapy in melanoma and other tumor types (102-104). In particular, the mechanisms responsible for BRAF (+/- MEK) inhibitor resistance can be divided into genomic (NRAS/KRAS mutation $20 \%, B R A F$ splice variants $16 \%, B R A F$ amplification $13 \%$, $M E K 1 / 2$ mutation $7 \%$, bypass track mutations $11 \%$ ), immunologic (epigenetic and transcriptomic changes of molecules involved in antigen presenting mechanisms) and a combination of both $(105,106)$.

Currently, the detection of the mechanisms responsible for BRAF and MEK inhibitor resistance is not part of standard clinical practice; however, the development of non-invasive techniques for tumor mutational status assessment may lead to more rapid changes in this setting (107). The technique termed 'liquid biopsy' enables the detection of tumor-derived circulating cell-free DNA (ctDNA) in the plasma and is emerging as a promising blood-based biomarker for monitoring the melanoma disease status. Several studies have indicated that $\mathrm{BRAF}^{\mathrm{V} 600 \mathrm{E}}$ detection through ctDNA prior to the commencement of treatment is predictive of the response to BRAF kinase inhibitors, and that high basal ctDNA levels are associated with a lower response rate and progression-free survival (107-109). Moreover, ctDNA is an indicator of tumor burden and tumor dynamics, and it has been demonstrated that an increase in ctDNA levels during treatment is indicative of disease progression and acquired resistance $(107,109)$. Notably, ctDNA can be used also for the detection of mutations responsible for resistance to BRAF targeted therapies and in the future, this can be used to guide subsequent treatment strategies $(107,109)$.

Immune checkpoint inhibitors are associated with a low overall response rate (ORR). This has driven considerable research efforts in the identification of biomarkers able to predict which patients will more likely benefit from these treatments. At this point, PD-L1 immunohistochemistry on tumor specimens is not a candidate marker for PD-1 inhibitor treatment response, due to the extremely heterogeneous results obtained from clinical trials $(88,99)$. Several other predictive biomarkers are currently under investigation. The specific components of melanoma microenvironment and in particular the $\mathrm{CD}^{+} \mathrm{T}$ cell activation, through IFN- $\gamma$ gene expression signature, has been associated with immunotherapy response $(110,111)$. Moreover, several studies have demonstrated the mechanisms through which specific genomic alterations can drive immune checkpoint resistance through the alteration of antigen-presenting mechanisms and IFN- $\gamma$ production (112-114). Recently, in humans, it has been demonstrated that specific gut microbiota compositions can drive differential responses to immune checkpoint inhibitors (115-117). This is not only a new intriguing field of research for immunotherapy biomarkers, but it also paves the way for the potential modulation of human gut microbiota composition to improve the immunotherapy response. As regards the identification of complex biological interactions among different pathways and their interplay with the immune system, bioinformatics has yielded promising results. In this context, computational models can simulate biochemical, metabolic and immune mediated interactions and characterize how they are potentially involved in melanoma development $(118,119)$. Overall, computational approaches may potentially lead to the identification of novel therapeutic targets and may accelerate the drug discovery process (120).

\section{Conclusions}

Marked improvements in melanoma treatment have been achieved over the past decade. The tireless efforts of researchers have shed light on essential mechanisms involved in melanoma biology, paving the way for targeted treatment and immunotherapy. However, melanoma remains a lethal type of cancer, particularly when diagnosed at an advanced stage. Further elucidation of melanoma biology and evolution also in presence of treatment-selective pressure represent a central goal of cancer research in this field and may ultimately improve patient care and prognosis.

\section{Acknowledgements}

Not applicable.

\section{Funding}

This study was supported by the Lega Italiana per la Lotta contro i Tumori (LILT) and the grant entitled: Identification of cancer driver genes for novel diagnostics and therapeutic strategies Piano per la ricerca 2016-2018 - Linea di intervento 2 - University of Catania, Department of Biomedical and Biotechnological Sciences.

\section{Availability of data and materials}

Not applicable.

\section{Authors' contributions}

GCL and LF wrote the manuscript and were involved in data collection. JAM, RS and AZ contributed to enriching the knowledge concerning the genesis of melanoma, the current medical treatment and the predictive biomarkers tested for the diagnosis of melanoma. SC was involved in the creation of the figures. ML, SC and DAS conceived the review and revised the manuscript. All authors edited the manuscript and have approved its final version.

\section{Ethics approval and consent to participate}

Not applicable. 


\section{Consent for publication}

Not applicable.

\section{Competing interests}

DAS is the Editor-in-Chief for the journal, but had no personal involvement in the reviewing process, or any influence in terms of adjudicating on the final decision, for this article. The remaining authors have no competing interests.

\section{References:}

1. Ali Z, Yousaf N and Larkin J: Melanoma epidemiology, biology and prognosis. EJC Suppl 11: 81-91, 2013.

2. Ferlay J, Soerjomataram I, Dikshit R, Eser S, Mathers C, Rebelo M, Parkin DM, Forman D and Bray F: Cancer incidence and mortality worldwide: Sources, methods and major patterns in GLOBOCAN 2012. Int J Cancer 136: E359-E386, 2015.

3. Rastrelli M, Tropea S, Rossi CR and Alaibac M: Melanoma: Epidemiology, risk factors, pathogenesis, diagnosis and classification. In Vivo 28: 1005-1011, 2014.

4. Gilchrest BA, Eller MS, Geller AC and Yaar M: The pathogenesis of melanoma induced by ultraviolet radiation. N Engl J Med 340 $1341-1348,1999$.

5. Pennello G, Devesa S and Gail M: Association of surface ultraviolet $\mathrm{B}$ radiation levels with melanoma and nonmelanoma skin cancer in United States blacks. Cancer Epidemiol Biomarkers Prev 9: 291-297, 2000.

6. Falzone L, Marconi A, Loreto C, Franco S, Spandidos DA and Libra M: Occupational exposure to carcinogens: Benzene, pesticides and fibers (Review). Mol Med Rep 14: 4467-4474, 2016.

7. Nelemans PJ, Groenendal H,Kiemeney LA, Rampen FH, Ruiter DJ and Verbeek AL: Effect of intermittent exposure to sunlight on melanoma risk among indoor workers and sun-sensitive individuals. Environ Health Perspect 101: 252-255, 1993.

8. Elwood JM and Jopson J: Melanoma and sun exposure: An overview of published studies. Int J Cancer 73: 198-203, 1997.

9. Candido S, Rapisarda V, Marconi A, Malaponte G, Bevelacqua V, Gangemi P, Scalisi A, McCubrey JA, Maestro R, Spandidos DA, et al: Analysis of the B-Raf ${ }^{\mathrm{V} 600 \mathrm{E}}$ mutation in cutaneous melanoma patients with occupational sun exposure. Oncol Rep 31: 1079-1082, 2014.

10. Gandini S, Sera F, Cattaruzza MS, Pasquini P, Picconi O, Boyle P and Melchi CF: Meta-analysis of risk factors for cutaneous melanoma: II. Sun exposure. Eur J Cancer 41: 45-60, 2005.

11. White E, Kirkpatrick CS and Lee JA: Case-control study of malignant melanoma in Washington state. I. Constitutional factors and sun exposure. Am J Epidemiol 139: 857-868, 1994.

12. Lazovich D, Vogel RI, Berwick M, Weinstock MA, Anderson KE and Warshaw EM: Indoor tanning and risk of melanoma: A case-control study in a highly exposed population. Cancer Epidemiol Biomarkers Prev 19: 1557-1568, 2010.

13. Archier E, Devaux S, Castela E, Gallini A, Aubin F, Le Maître M, Aractingi S, Bachelez H, Cribier B, Joly P, et al: Carcinogenic risks of psoralen UV-A therapy and narrowband UV-B therapy in chronic plaque psoriasis: A systematic literature review. J Eur Acad Dermatol Venereol 26 (Suppl 3): 22-31, 2012.

14. International Agency for Research on Cancer Working Group on artificial ultraviolet (UV) light and skin cancer: The association of use of sunbeds with cutaneous malignant melanoma and other skin cancers: A systematic review. Int J Cancer 120: 1116-1122, 2007.

15. Wehner MR, Chren MM, Nameth D, Choudhry A, Gaskins M, Nead KT, Boscardin WJ and Linos E: International prevalence of indoor tanning: A systematic review and meta-analysis. JAMA Dermatol 150: 390-400, 2014

16. Bauer J and Garbe C: Acquired melanocytic nevi as risk factor for melanoma development. A comprehensive review of epidemiological data. Pigment Cell Res 16: 297-306, 2003.

17. Russo AE, Torrisi E, Bevelacqua Y, Perrotta R, Libra M, McCubrey JA, Spandidos DA, Stivala F and Malaponte G: Melanoma: Molecular pathogenesis and emerging target therapies (Review). Int J Oncol 34: 1481-1489, 2009.
18. Hawkes JE, Truong A and Meyer LJ: Genetic predisposition to melanoma. Semin Oncol 43: 591-597, 2016.

19. Bevona C, Goggins W, Quinn T, Fullerton J and Tsao $\mathrm{H}$ : Cutaneous melanomas associated with nevi. Arch Dermatol 139: 1620-1624, discussion 1624, 2003.

20. Seykora J and Elder D: Dysplastic nevi and other risk markers for melanoma. Semin Oncol 23: 682-687, 1996.

21. Watt AJ, Kotsis SV and Chung KC: Risk of melanoma arising in large congenital melanocytic nevi: A systematic review. Plast Reconstr Surg 113: 1968-1974, 2004.

22. Gandini S, Sera F, Cattaruzza MS, Pasquini P, Abeni D, Boyle P and Melchi CF: Meta-analysis of risk factors for cutaneous melanoma: I. Common and atypical naevi. Eur J Cancer 41: 28-44, 2005.

23. Olsen CM, Zens MS, Stukel TA, Sacerdote C, Chang YM, Armstrong BK, Bataille V, Berwick M, Elwood JM, Holly EA, et al: Nevus density and melanoma risk in women: A pooled analysis to test the divergent pathway hypothesis. Int J Cancer 124: 937-944, 2009.

24. Dessinioti C, Antoniou C, Katsambas A and Stratigos AJ: Melanocortin 1 receptor variants: Functional role and pigmentary associations. Photochem Photobiol 87: 978-987, 2011.

25. Goldstein AM and Tucker MA: Genetic epidemiology of cutaneous melanoma: A global perspective. Arch Dermatol 137: 1493-1496, 2001

26. Soura E, Eliades PJ, Shannon K, Stratigos AJ and Tsao H: Hereditary melanoma: Update on syndromes and management: Genetics of familial atypical multiple mole melanoma syndrome. J Am Acad Dermatol 74: 395-407, quiz 408-410, 2016.

27. Gruis NA, van der Velden PA, Sandkuijl LA, Prins DE, WeaverFeldhaus J, Kamb A, Bergman W and Frants RR: Homozygotes for CDKN2 (p16) germline mutation in Dutch familial melanoma kindreds. Nat Genet 10: 351-353, 1995.

28. Zuo L, Weger J, Yang Q, Goldstein AM, Tucker MA, Walker GJ, Hayward N and Dracopoli NC: Germline mutations in the p16INK4a binding domain of CDK4 in familial melanoma. Nat Genet 12: 97-99, 1996

29. Kanitakis J: Anatomy, histology and immunohistochemistry of normal human skin. Eur J Dermatol 12: 390-399, quiz 400-401, 2002.

30. Lin JY and Fisher DE: Melanocyte biology and skin pigmentation. Nature 445: 843-850, 2007.

31. Curtin JA, Fridlyand J, Kageshita T, Patel HN, Busam KJ, Kutzner H, Cho KH, Aiba S, Bröcker EB, LeBoit PE, et al: Distinct sets of genetic alterations in melanoma. N Engl J Med 353: 2135-2147, 2005.

32. Bastian BC: The molecular pathology of melanoma: An integrated taxonomy of melanocytic neoplasia. Annu Rev Pathol 9: 239-271, 2014.

33. Shain AH and Bastian BC: From melanocytes to melanomas. Nat Rev Cancer 16: 345-358, 2016.

34. Pollock PM, Harper UL, Hansen KS, Yudt LM, Stark M, Robbins CM, Moses TY, Hostetter G, Wagner U, Kakareka J, et al: High frequency of BRAF mutations in nevi. Nat Genet 33: 19-20, 2003.

35. Leonardi GC, Accardi G, Monastero R, Nicoletti F and Libra M: Ageing: From inflammation to cancer. Immun Ageing 15: 1, 2018.

36. Speeckaert R, van Geel N, Vermaelen KV, Lambert J, Van Gele M, Speeckaert MM and Brochez L: Immune reactions in benign and malignant melanocytic lesions: Lessons for immunotherapy. Pigment Cell Melanoma Res 24: 334-344, 2011.

37. Gray-Schopfer V, Wellbrock C and Marais R: Melanoma biology and new targeted therapy. Nature 445: 851-857, 2007.

38. Farmer ER, Gonin R and Hanna MP: Discordance in the histopathologic diagnosis of melanoma and melanocytic nevi between expert pathologists. Hum Pathol 27: 528-531, 1996.

39. Chiriboga L, Meehan S, Osman I, Glick M, de la Cruz G, Howell BS, Friedman-Jiménez G, Schneider RJ and Jamal S: Endothelin-1 in the tumor microenvironment correlates with melanoma invasion. Melanoma Res 26: 236-244, 2016.

40. Moro N, Mauch C and Zigrino P: Metalloproteinases in melanoma. Eur J Cell Biol 93: 23-29, 2014.

41. Sandri S, Faião-Flores F, Tiago M, Pennacchi PC, Massaro RR, Alves-Fernandes DK, Berardinelli GN, Evangelista AF, de Lima Vazquez V, Reis RM and Maria-Engler SS: Vemurafenib resistance increases melanoma invasiveness and modulates the tumor microenvironment by MMP-2 upregulation. Pharmacol Res 111: 523-533, 2016. 
42. Falzone L, Salemi R, Travali S, Scalisi A, McCubrey JA Candido $\mathrm{S}$ and Libra M: MMP-9 overexpression is associated with intragenic hypermethylation of MMP9 gene in melanoma. Aging (Albany NY) 8: 933-944, 2016.

43. Lee KR, Lee JS, Kim YR, Song IG and Hong EK: Polysaccharide from Inonotus obliquus inhibits migration and invasion in B16-F10 cells by suppressing MMP-2 and MMP-9 via downregulation of NF-кB signaling pathway. Oncol Rep 31: 2447-2453, 2014.

44. Guarneri C, Bevelacqua V, Polesel J, Falzone L, Cannavò PS, Spandidos DA, Malaponte G and Libra M: NF- $\kappa$ B inhibition is associated with OPN/MMP 9 downregulation in cutaneous melanoma. Oncol Rep 37: 737-746, 2017.

45. Vogelstein B,Papadopoulos N, Velculescu VE,Zhou S, Diaz LA Jr and Kinzler KW: Cancer genome landscapes. Science 339: 1546-1558, 2013.

46. Akbani R, Akdemir KC, Aksoy BA, Albert M, Ally A, Amin SB, Arachchi H, Arora A, Auman JT, Ayala B, et al; Cancer Genome Atlas Network: Genomic classification of cutaneous melanoma. Cell 161: 1681-1696, 2015.

47. Hodis E, Watson IR, Kryukov GV, Arold ST, Imielinski M, Theurillat JP, Nickerson E, Auclair D, Li L, Place C, et al: A landscape of driver mutations in melanoma. Cell 150: 251-263, 2012.

48. Krauthammer M, Kong Y, Ha BH, Evans P, Bacchiocchi A, McCusker JP, Cheng E, Davis MJ, Goh G, Choi M, et al: Exome sequencing identifies recurrent somatic RAC1 mutations in melanoma. Nat Genet 44: 1006-1014, 2012.

49. Chappell WH, Steelman LS, Long JM, Kempf RC, Abrams SL, Franklin RA, Bäsecke J, Stivala F, Donia M, Fagone P, et al: Ras/Raf/MEK/ERK and PI3K/PTEN/Akt/mTOR inhibitors: Rationale and importance to inhibiting these pathways in human health. Oncotarget 2: 135-164, 2011.

50. Wellbrock C, Karasarides M and Marais R: The RAF proteins take centre stage. Nat Rev Mol Cell Biol 5: 875-885, 2004.

51. Raman M, Chen W and Cobb MH: Differential regulation and properties of MAPKs. Oncogene 26: 3100-3112, 2007.

52. Carlino MS, Long GV, Kefford RF and Rizos H: Targeting oncogenic BRAF and aberrant MAPK activation in the treatment of cutaneous melanoma. Crit Rev Oncol Hematol 96: 385-398, 2015.

53. Yuan TL and Cantley LC: PI3K pathway alterations in cancer: Variations on a theme. Oncogene 27: 5497-5510, 2008.

54. Davies MA: The role of the PI3K-AKT pathway in melanoma. Cancer J 18: 142-147, 2012

55. Cohen C, Zavala-Pompa A, Sequeira JH, Shoji M, Sexton DG, Cotsonis G, Cerimele F, Govindarajan B, Macaron N and Arbiser JL: Mitogen-actived protein kinase activation is an early event in melanoma progression. Clin Cancer Res 8: 3728-3733, 2002.

56. Wang YF, Jiang CC, Kiejda KA, Gillespie S, Zhang XD and Hersey P: Apoptosis induction in human melanoma cells by inhibition of MEK is caspase-independent and mediated by the Bcl-2 family members PUMA, Bim, and Mcl-1. Clin Cancer Res 13: 4934-4942, 2007.

57. Lovly CM, Dahlman KB, Fohn LE, Su Z, Dias-Santagata D, Hicks DJ, Hucks D, Berry E, Terry C, Duke M, et al: Routine multiplex mutational profiling of melanomas enables enrollment in genotype-driven therapeutic trials. PLoS One 7: e35309, 2012.

58. Rubinstein JC, Sznol M, Pavlick AC, Ariyan S, Cheng E, Bacchiocchi A, Kluger HM, Narayan D and Halaban R: Incidence of the V600K mutation among melanoma patients with BRAF mutations, and potential therapeutic response to the specific BRAF inhibitor PLX4032. J Transl Med 8: 67, 2010.

59. Davies H, Bignell GR, Cox C, Stephens P, Edkins S, Clegg S, Teague J, Woffendin H, Garnett MJ, Bottomley W, et al: Mutations of the BRAF gene in human cancer. Nature 417: 949-954, 2002

60. Wan PTC, Garnett MJ, Roe SM, Lee S, Niculescu-Duvaz D, Good VM, Jones CM, Marshall CJ, Springer CJ, Barford D and Marais R; Cancer Genome Project: Mechanism of activation of the RAF-ERK signaling pathway by oncogenic mutations of B-RAF. Cell 116: 855-867, 2004

61. Richtig G, Hoeller C, Kashofer K, Aigelsreiter A, Heinemann A, Kwong LN, Pichler $M$ and Richtig E: Beyond the BRAF ${ }^{\mathrm{V} 600 \mathrm{E}}$ hotspot: Biology and clinical implications of rare BRAF gene mutations in melanoma patients. Br J Dermatol 177: 936-944, 2017.

62. Jakob JA, Bassett RL Jr, Ng CS, Curry JL, Joseph RW, Alvarado GC, Rohlfs ML, Richard J, Gershenwald JE, Kim KB, et al: NRAS mutation status is an independent prognostic factor in metastatic melanoma. Cancer 118: 4014-4023, 2012.

63. Giehl K: Oncogenic Ras in tumour progression and metastasis. Biol Chem 386: 193-205, 2005.
64. Fedorenko IV, Gibney GT and Smalley KS: NRAS mutant melanoma: Biological behavior and future strategies for therapeutic management. Oncogene 32: 3009-3018, 2013.

65. Maertens O, Johnson B, Hollstein P, Frederick DT, Cooper ZA, Messiaen L, Bronson RT, McMahon M, Granter S, Flaherty K, et al: Elucidating distinct roles for NF1 in melanomagenesis. Cancer Discov 3: 338-349, 2013.

66. Whittaker SR, Theurillat JP, Van Allen E, Wagle N, Hsiao J, Cowley GS, Schadendorf D, Root DE and Garraway LA: A genome-scale RNA interference screen implicates NF1 loss in resistance to RAF inhibition. Cancer Discov 3: 350-362, 2013.

67. Nissan MH, Pratilas CA, Jones AM, Ramirez R, Won H, Liu C, Tiwari S, Kong L, Hanrahan AJ, Yao Z, et al: Loss of NF1 in cutaneous melanoma is associated with RAS activation and MEK dependence. Cancer Res 74: 2340-2350, 2014.

68. Krauthammer M, Kong Y, Bacchiocchi A, Evans P, Pornputtapong N, Wu C, McCusker JP, Ma S, Cheng E, Straub R, et al: Exome sequencing identifies recurrent mutations in NF1 and RASopathy genes in sun-exposed melanomas. Nat Genet 47: 996-1002, 2015.

69. Gibney GT and Smalley KS: An unholy alliance: Cooperation between BRAF and NF1 in melanoma development and BRAF inhibitor resistance. Cancer Discov 3: 260-263, 2013.

70. Beadling C, Jacobson-Dunlop E, Hodi FS, Le C, Warrick A, Patterson J, Town A, Harlow A, Cruz F III, Azar S, et al: KIT gene mutations and copy number in melanoma subtypes. Clin Cancer Res 14: 6821-6828, 2008.

71. Handolias D, Salemi R, Murray W, Tan A, Liu W, Viros A, Dobrovic A, Kelly J and McArthur GA: Mutations in KIT occur at low frequency in melanomas arising from anatomical sites associated with chronic and intermittent sun exposure. Pigment Cell Melanoma Res 23: 210-215, 2010.

72. Shain AH, Yeh I, Kovalyshyn I, Sriharan A, Talevich E, Gagnon A, Dummer R, North J, Pincus L, Ruben B, et al: The genetic evolution of melanoma from precursor lesions. N Engl J Med 373: 1926-1936, 2015.

73. Castellano M, Pollock PM, Walters MK, Sparrow LE, Down LM, Gabrielli BG, Parsons PG and Hayward NK: CDKN2A/p16 is inactivated in most melanoma cell lines. Cancer Res 57:4868-4875, 1997.

74. Sharpless E and Chin L: The INK4a/ARF locus and melanoma. Oncogene 22: 3092-3098, 2003.

75. Wu H, Goel V and Haluska FG: PTEN signaling pathways in melanoma. Oncogene 22: 3113-3122, 2003.

76. Mirmohammadsadegh A, Marini A, Nambiar S, Hassan M, Tannapfel A, Ruzicka T and Hengge UR: Epigenetic silencing of the PTEN gene in melanoma. Cancer Res 66: 6546-6552, 2006.

77. Stahl JM, Cheung M, Sharma A, Trivedi NR, Shanmugam S and Robertson GP: Loss of PTEN promotes tumor development in malignant melanoma. Cancer Res 63: 2881-2890, 2003.

78. Tsao H, Goel V, Wu H, Yang G and Haluska FG: Genetic interaction between NRAS and BRAF mutations and PTEN/MMAC1 inactivation in melanoma. J Invest Dermatol 122: 337-341, 2004.

79. Nogueira C, Kim KH, Sung H, Paraiso KH, Dannenberg JH, Bosenberg M, Chin L and Kim M: Cooperative interactions of PTEN deficiency and RAS activation in melanoma metastasis. Oncogene 29: 6222-6232, 2010.

80. Shi H, Hugo W, Kong X, Hong A, Koya RC, Moriceau G, Chodon T, Guo R, Johnson DB, Dahlman KB, et al: Acquired resistance and clonal evolution in melanoma during BRAF inhibitor therapy. Cancer Discov 4: 80-93, 2014.

81. Damsky WE, Curley DP, Santhanakrishnan M, Rosenbaum LE, Platt JT, Gould Rothberg BE, Taketo MM, Dankort D, Rimm DL, McMahon $\mathrm{M}$ and Bosenberg $\mathrm{M}$ : $\beta$-catenin signaling controls metastasis in Braf-activated Pten-deficient melanomas. Cancer Cell 20: 741-754, 2011.

82. Rimm DL, Caca K, Hu G, Harrison FB and Fearon ER: Frequent nuclear/cytoplasmic localization of $\beta$-catenin without exon 3 mutations in malignant melanoma. Am J Pathol 154: 325-329, 1999.

83. Ross MI and Gershenwald JE: Evidence-based treatment of early-stage melanoma. J Surg Oncol 104: 341-353, 2011.

84. Luke JJ, Flaherty KT, Ribas A and Long GV: Targeted agents and immunotherapies: Optimizing outcomes in melanoma. Nat Rev Clin Oncol 14: 463-482, 2017

85. Hodi FS, O'Day SJ, McDermott DF, Weber RW, Sosman JA, Haanen JB, Gonzalez R, Robert C, Schadendorf D, Hassel JC, et al: Improved survival with ipilimumab in patients with metastatic melanoma. N Engl J Med 363: 711-723, 2010. 
86. Hauschild A, Grob JJ, Demidov LV, Jouary T, Gutzmer R, Millward M, Rutkowski P, Blank CU, Miller WH Jr, Kaempgen E, et al: Dabrafenib in BRAF-mutated metastatic melanoma: A multicentre, open-label, phase 3 randomised controlled trial. Lancet 380: 358-365, 2012.

87. McArthur GA, Chapman PB, Robert C, Larkin J, Haanen JB, Dummer R, Ribas A, Hogg D, Hamid O, Ascierto PA, et al: Safety and efficacy of vemurafenib in BRAF(V600E) and BRAF(V600K) mutation-positive melanoma (BRIM-3): Extended follow-up of a phase 3, randomised, open-label study. Lancet Oncol 15: 323-332, 2014

88. Robert C, Long GV, Brady B, Dutriaux C, Maio M, Mortier L, Hassel JC, Rutkowski P, McNeil C, Kalinka-Warzocha E, et al: Nivolumab in previously untreated melanoma without BRAF mutation. N Engl J Med 372: 320-330, 2015.

89. Robert C, Karaszewska B, Schachter J,Rutkowski P, Mackiewicz A, Stroiakovski D, Lichinitser M, Dummer R, Grange F, Mortier L, et al: Improved overall survival in melanoma with combined dabrafenib and trametinib. N Engl J Med 372: 30-39, 2015.

90. Long GV, Stroyakovskiy D, Gogas H, Levchenko E, de Braud F, Larkin J, Garbe C, Jouary T, Hauschild A, Grob JJ, et al: Dabrafenib and trametinib versus dabrafenib and placebo for Val600 BRAF-mutant melanoma: A multicentre, double-blind, phase 3 randomised controlled trial. Lancet 386: 444-451, 2015.

91. Ribas A, Puzanov I, Dummer R, Schadendorf D, Hamid O Robert C, Hodi FS, Schachter J, Pavlick AC, Lewis KD, et al: Pembrolizumab versus investigator-choice chemotherapy for ipilimumab-refractory melanoma (KEYNOTE-002): A randomised, controlled, phase 2 trial. Lancet Oncol 16: 908-918, 2015.

92. Weber JS, D'Angelo SP, Minor D, Hodi FS, Gutzmer R, Neyns B, Hoeller C, Khushalani NI, Miller WH Jr, Lao CD, et al: Nivolumab versus chemotherapy in patients with advanced melanoma who progressed after anti-CTLA-4 treatment (CheckMate 037): A randomised, controlled, open-label, phase 3 trial. Lancet Oncol 16 375-384, 2015

93. Ascierto PA, McArthur GA, Dréno B, Atkinson V, Liszkay G, Di Giacomo AM, Mandalà M, Demidov L, Stroyakovskiy D, Thomas L, et al: Cobimetinib combined with vemurafenib in advanced BRAF(V600)-mutant melanoma (coBRIM): Updated efficacy results from a randomised, double-blind, phase 3 trial. Lancet Oncol 17: 1248-1260, 2016.

94. Malas S, Harrasser M, Lacy KE and Karagiannis SN: Antibody therapies for melanoma: New and emerging opportunities to activate immunity (Review). Oncol Rep 32: 875-886, 2014

95.Zhang Y, Song Y and Gao Q: Increased survival time of a patient with metastatic malignant melanoma following immunotherapy: A case report and literature review. Oncol Lett 10: 883-886, 2015

96. Akiyama Y, Nonomura C, Kondou R, Miyata H, Ashizawa T, Maeda C, Mitsuya K, Hayashi N, Nakasu Y and Yamaguchi K Immunological effects of the anti-programmed death-1 antibody on human peripheral blood mononuclear cells. Int J Oncol 49: 1099-1107, 2016.

97. Larkin J, Lao CD, Urba WJ, McDermott DF, Horak C, Jiang J and Wolchok JD: Efficacy and safety of nivolumab in patients with BRAF V600 mutant and BRAF wild-type advanced melanoma: A pooled analysis of 4 clinical trials. JAMA Oncol 1: 433-440, 2015.

98. Mangana J, Cheng PF, Schindler K, Weide B, Held U, Frauchiger AL, Romano E, Kähler KC, Rozati S, Rechsteiner M et al: Analysis of BRAF and NRAS mutation status in advanced melanoma patients treated with anti-CTLA 4 antibodies: Association with overall survival? PLoS One 10: e0139438, 2015

99. Robert C, Schachter J, Long GV, Arance A, Grob JJ, Mortier L, Daud A, Carlino MS, McNeil C, Lotem M, et al; KEYNOTE-006 investigators: Pembrolizumab versus ipilimumab in advanced melanoma. N Engl J Med 372: 2521-2532, 2015.

100. Simeone E and Ascierto PA: Immunomodulating antibodies in the treatment of metastatic melanoma: The experience with anti-CTLA-4, anti-CD137, and anti-PD1. J Immunotoxicol 9: 241-247, 2012

101.Zimmer L, Apuri S, Eroglu Z, Kottschade LA, Forschner A, Gutzmer R, Schlaak M, Heinzerling L, Krackhardt AM, Loquai C, et al: Ipilimumab alone or in combination with nivolumab after progression on anti-PD-1 therapy in advanced melanoma. Eur J Cancer 75: 47-55, 2017

102. McCubrey JA, Steelman LS, Kempf CR, Chappell WH, Abrams SL, Stivala F, Malaponte G, Nicoletti F, Libra M, Bäsecke J, et al: Therapeutic resistance resulting from mutations in Raf/MEK/ERK and PI3K/PTEN/Akt/mTOR signaling pathways. J Cell Physiol 226: 2762-2781, 2011.
103. Steelman LS, Chappell WH, Abrams SL, Kempf RC, Long J, Laidler P, Mijatovic S, Maksimovic-Ivanic D, Stivala F, Mazzarino MC, et al: Roles of the Raf/MEK/ERK and PI3K/ PTEN/Akt/mTOR pathways in controlling growth and sensitivity to therapy-implications for cancer and aging. Aging (Albany NY) 3: 192-222, 2011.

104. McCubreyJA,SteelmanLS,ChappellWH,Abrams SL,FranklinRA, Montalto G, Cervello M, Libra M, Candido S, Malaponte G, et al: Ras/Raf/MEK/ERK and PI3K/PTEN/Akt/mTOR cascade inhibitors: How mutations can result in therapy resistance and how to overcome resistance. Oncotarget 3: 1068-1111, 2012.

105. Van Allen EM, Wagle N, Sucker A, Treacy DJ, Johannessen CM, Goetz EM, Place CS, Taylor-Weiner A, Whittaker S, Kryukov GV, et al; Dermatologic Cooperative Oncology Group of Germany (DeCOG): The genetic landscape of clinical resistance to RAF inhibition in metastatic melanoma. Cancer Discov 4: 94-109, 2014.

106. Hugo W, Shi H, Sun L, Piva M, Song C, Kong X, Moriceau G, Hong A, Dahlman KB, Johnson DB, et al: Non-genomic and immune evolution of melanoma acquiring MAPKi resistance. Cell 162: 1271-1285, 2015

107. Gray ES, Rizos H, Reid AL, Boyd SC, Pereira MR, Lo J, Tembe V, Freeman J, Lee JH, Scolyer RA, et al: Circulating tumor DNA to monitor treatment response and detect acquired resistance in patients with metastatic melanoma. Oncotarget 6: 42008-42018, 2015

108. Santiago-Walker A, Gagnon R, Mazumdar J, Casey M, Long GV, Schadendorf D, Flaherty K, Kefford R, Hauschild A, Hwu P, et al: Correlation of BRAF Mutation status in circulating-free dna and tumor and association with clinical outcome across four BRAFi and MEKi clinical trials. Clin Cancer Res 22: 567-574, 2016.

109. Girotti MR, Gremel G, Lee R, Galvani E, Rothwell D, Viros A, Mandal AK, Lim KH, Saturno G, Furney SJ, et al: Application of sequencing, liquid biopsies, and patient-derived xenografts for personalized medicine in melanoma. Cancer Discov 6: 286-299, 2016.

110. Spranger S, Spaapen RM, Zha Y, Williams J, Meng Y, Ha TT and Gajewski TF: Up-regulation of PD-L1, IDO, and T(regs) in the melanoma tumor microenvironment is driven by CD $8(+)$ T cells. Sci Transl Med 5: 200ra116, 2013.

111. Donia M, Harbst K, van Buuren M, Kvistborg P, Lindberg MF, Andersen R, Idorn M, Munir Ahmad S, Ellebæk E, Mueller A, et al: Acquired immune resistance follows complete tumor regression without loss of target antigens or IFN $\gamma$ signaling. Cancer Res 77: 4562-4566, 2017.

112. Spranger S, Bao R and Gajewski TF: Melanoma-intrinsic $\beta$-catenin signalling prevents anti-tumour immunity. Nature 523 231-235, 2015

113. Peng W, Chen JQ, Liu C, Malu S, Creasy C, Tetzlaff MT, Xu C, McKenzie JA, Zhang C, Liang X, et al: Loss of PTEN promotes resistance to T cell-mediated immunotherapy. Cancer Discov 6: 202-216, 2016

114.Zaretsky JM, Garcia-Diaz A, Shin DS, Escuin-Ordinas H, Hugo W, Hu-Lieskovan S, Torrejon DY, Abril-Rodriguez G, Sandoval S, Barthly L, et al: Mutations associated with acquired resistance to PD 1 blockade in melanoma. N Engl J Med 375: 819-829, 2016

115. Banna GL, Torino F, Marletta F, Santagati M, Salemi R, Cannarozzo E, Falzone L, Ferraù F and Libra M: Lactobacillus rhamnosus GG: An overview to explore the rationale of its use in cancer. Front Pharmacol 1: 8: 603, 2017.

116. Gopalakrishnan V, Spencer CN, Nezi L, Reuben A, Andrews MC Karpinets TV, Prieto PA, Vicente D, Hoffman K, Wei SC, et al: Gut microbiome modulates response to anti-PD-1 immunotherapy in melanoma patients. Science 359: 97-103, 2018.

117. Routy B, Le Chatelier E, Derosa L, Duong CPM, Alou MT, Daillère R, Fluckiger A, Messaoudene M, Rauber C, Roberti MP, et al: Gut microbiome influences efficacy of PD-1-based immunotherapy against epithelial tumors. Science 359: 91-97, 2018

118. Pappalardo F, Russo G, Candido S, Pennisi M, Cavalieri S, Motta S, McCubrey JA, Nicoletti F and Libra M: Computational modeling of PI3K/AKT and MAPK signaling pathways in melanoma Cancer. PLoS One 11: e0152104, 2016.

119. Rambow F, Job B, Petit V, Gesbert F, Delmas V, Seberg H, Meurice G, Van Otterloo E, Dessen P, Robert C, et al: New functional signatures for understanding melanoma biology from tumor cell lineage-specific analysis. Cell Reports 13: 840-853, 2015. 
120.Pennisi M, Russo G, Di Salvatore V, Candido S, Libra M and Pappalardo F: Computational modeling in melanoma for novel drug discovery. Expert Opin Drug Discov 11: 609-621, 2016.

121. Chapman PB, Hauschild A, Robert C, Haanen JB, Ascierto P, Larkin J, Dummer R, Garbe C, Testori A, Maio M, et al; BRIM-3 Study Group: Improved survival with vemurafenib in melanoma with BRAF V600E mutation. N Engl J Med 364: 2507-2516, 2011.

122. Robert C, Thomas L, Bondarenko I, O'Day S, Weber J, Garbe C, Lebbe C, Baurain JF, Testori A, Grob JJ, et al: Ipilimumab plus dacarbazine for previously untreated metastatic melanoma. N Engl J Med 364: 2517-2526, 2011.

123. Wolchok JD, Chiarion-Sileni V, Gonzalez R, Rutkowski P, Grob JJ, Cowey CL, Lao CD, Wagstaff J, Schadendorf D, Ferrucci PF, et al: Overall survival with combined nivolumab and ipilimumab in advanced melanoma. N Engl J Med 377: 1345-1356, 2017.
124. Schachter J, Ribas A, Long GV, Arance A, Grob JJ, Mortier L, Daud A, Carlino MS, McNeil C, Lotem M, et al: Pembrolizumab versus ipilimumab for advanced melanoma: Final overall survival results of a multicentre, randomised, open-label phase 3 study (KEYNOTE-006). Lancet 390: 1853-1862, 2017.

(i) (3) This work is licensed under a Creative Commons Attribution-NonCommercial-NoDerivatives 4.0 International (CC BY-NC-ND 4.0) License. 